\title{
Mechanistic Insights into Phosphatase Triggered Self-Assembly Including Enhancement of Biocatalytic Conversion Rate
}

\author{
Kate Thornton, ${ }^{a}$ Yousef M. Abul-Haija, ${ }^{b}$ Nigel Hodson ${ }^{c}$ and Rein V. Ulijn* ${ }^{b}$
}

We report on the mechanistic investigation of alkaline phosphatase (AP) triggered self-assembly and hydrogelation of Fmoc-Tyrosine (Fmoc-Y). We studied separately the biocatalytic conversion using HPLC, changes in supramolecular interactions and chirality using CD and fluorescence spectroscopy, nanostructure formation by AFM and gelation by oscillatory rheometry. Three consecutive stages could be distinguished (which may overlap, depending on the enzyme concentration). Typically, the phosphorylated Fmoc-Y (Fmoc- $p \mathrm{Y}$ ) undergoes rapid and complete dephosphorylation, followed by formation of aggregates which reorganise into nanofibres and consequently give rise to gelation. We observed a remarkable enhancement of catalytic activity during the early stages of the self-assembly process, providing evidence for enhancement of enzymatic activation by the supramolecular structures formed. Overall, this study provides a further step in understanding biocatalytic self-assembly.

\section{Introduction}

Supramolecular hydrogels based on peptides and their derivatives are of interest for biomedical and nanotechnological applications. ${ }^{1-5} \mathrm{~A}$ range of triggers have been exploited to control self-assembly including changes in $\mathrm{pH}$, ionic strength, solvent polarity, exposure to light. ${ }^{6-10}$ An alternative approach is the utilisation of catalytic activity of enzymes to convert nonassembling precursors into self-assembly building blocks. ${ }^{11-17}$ Biocatalytic self-assembly is of interest for a number of reasons: (i) it enables triggered assembly under constant, physiological 
conditions; ${ }^{18}$ (ii) it enables exploitation of biocatalytic events which are specific to certain cell types or diseased states; ${ }^{19,20}$ (iii) catalysis inherently involves molecular amplification, which may be exploited in sensing and controlled release; (iv) it provides new tools for bottom-up nanofabrication by taking advantage of the ability to spatially and kinetically control the selfassembly process; ${ }^{21}$ (v) thermodynamically controlled systems provide new routes towards discovery of peptide based nanostructures by exploiting reversible exchange of amino acid sequences in dynamic peptide libraries. ${ }^{22-24}$

Most studies of self-assembling systems based on aromatic peptide amphiphiles have focused on characterisation of the final gels formed, and less on the route towards gelation. ${ }^{25-30}$ Adams et al. provided a mechanistic study of self-assembly and gelation of a range of naphtylpeptide derivatives, where the $\mathrm{pH}$ is lowered in a controlled manner via the hydrolysis of gluconolactone (GdL). ${ }^{31,32}$ Tang et al. studied the $\mathrm{pH}$ dependant self-assembly behaviour of Fmoc-FF (diphenylalanine), demonstrating formation of fibrils that laterally assembled to form tape-like structures. ${ }^{33}$

Biocatalytic self-assembly, whereby building blocks are produced by hydrolysis, ${ }^{15,21,34}$ or condensation of precursors, ${ }^{22,23}$ may be expected to be mechanistically different from $\mathrm{pH}$ controlled assembly in a number of ways. We previously demonstrated that enzymatic dephosphorylation of Fmoc-FpY gives rise to a transformation of micelles to chiral, unidirectional fibres. ${ }^{34}$ A similar supramolecular transformation was previously demonstrated for an aliphatic peptide amphiphile upon triggering with a matrix metalloproteinase enzyme. ${ }^{35}$

It is reasonable to expect the localised formation of building blocks at the site of catalysis to result in (temporary) enhancement of local concentrations of self-assembly building blocks. 
The nature and activity of the enzyme may therefore influence nucleation and structure growth. Indeed, the self-assembly process and properties of assembling materials can be tuned by varying enzyme concentrations. ${ }^{36}$ By taking advantage of the arrested dynamics associated with gelation ('locking' of the supramolecular structure), ${ }^{24}$ this allows for the precise control of self-assembly kinetics to access non-equilibrium conformations. ${ }^{21}$

In the current article, we investigated the mechanism and kinetics of the phosphatase triggered self-assembly of 9-fluorenylmethoxycarbonyl-phospho-tyrosine (Fmoc- $p \mathrm{Y}){ }^{12}$ as a model system. This system was developed by Yang and $\mathrm{Xu}$ and is, to our knowledge, still the simplest biocatalytic self-assembly system available. We study separately the biocatalytic conversion, changes in supramolecular interactions and chirality, nanostructure formation and gelation at varying enzyme concentrations giving rise to new mechanistic insights into the multistage self-assembly process, as illustrated in Figure 1.

\section{Experimental}

\section{Materials}

Fmoc- $p \mathrm{Y}$ was purchased from Fluka and used without further purification. The purity was $>98 \%$ as determined by reverse phase HPLC. AP, lyophilized from bovine intestinal mucosa, and the remaining solvents and chemicals were purchased from Sigma-Aldrich.

\section{Phosphatase triggered self-assembly}

In all cases a solution of Fmoc- $p \mathrm{Y}(40 \mathrm{mM})$ was prepared in alkaline phosphate buffer (0.6 M Dipotassium Phosphate (Fisher Scientific) with $1 \mathrm{mM}$ Magnesium Chloride (Sigma), pH 9), forming a clear solution. The $\mathrm{pH}$ was measured with a Hanna micro $\mathrm{pH}$ electrode linked to a 
Hanna pH 210 microprocessor $\mathrm{pH}$ meter and adjusted to neutral via the drop wise addition of either concentrated sodium hydroxide $(0.5 \mathrm{M} \mathrm{NaOH})$ or hydrochloric acid $(0.1 \mathrm{M} \mathrm{HCl})$ whilst vortexing to ensure a homogenous $\mathrm{pH}(\mathrm{pH} 7$ with a concentration of $0.15 \mathrm{M}$ Dipotassium Phosphate). Stable self-supporting hydrogels formed upon addition of AP, prepared at varying concentrations of $1.1 \times 10^{-3}$ to $0.11 \mathrm{mgs}$ of proteins in $100 \mu 1$ in phosphate buffer $(0.6 \mathrm{M})$. AP solution (100 $\mu$ l, varying concentrations) were added to the Fmoc- $p$ Y precursor solution (1 ml).

\section{Reverse Phase HPLC}

Samples were prepared by mixing a $10 \mu 1$ sample (solution or gel) in a $990 \mu 1$ solution containing 40:60 (V/V) acetonitrile/water with $0.1 \%$ trifluoro acetic acid (TFA). The samples $(100 \mu 1)$ were then passed through a Dionex P680 HPLC system equipped with a Nucleosil C18 column (length $25 \mathrm{~cm}$, width $4.6 \mathrm{~mm}$ and a particle size of $5 \mu \mathrm{m}$ ) and a UVID170 U detector at a wavelength of $210 \mathrm{~nm}$ was used to quantify the conversion to Fmoc- $p$ Y to Fmoc-Y. The gradient used was a linear exchange between $40 \%$ acetonitrile in water with $0.1 \%$ TFA at 2.5 min to $90 \%$ acetonitrile with water and $0.1 \%$ TFA at 23 min using a flow rate of $1 \mathrm{ml} \mathrm{min}^{-1}$.

\section{Fluorescence Spectroscopy}

Changes in the fluorenyl environment were investigated by fluorescence spectroscopy, focusing on the intensity of fluorenyl monomer peak (centred at $320 \mathrm{~nm}$ ) and the peak centred at $375 \mathrm{~nm}$, thought to represent fluorenyl aggregates in micelles. ${ }^{34}$ Solutions of Fmoc-pY (3 ml) were prepared and pipetted into a PMMA disposable cuvette of $1 \mathrm{~cm}$ width (Fisher Scientific). Emission spectra were recorded prior to AP addition $(300 \mu \mathrm{l})$ and at specific time points afterwards (Jasco FP-6500 with a Julabo F12 water bath and Juablo ED temperature control) for the duration of the time course. The emission spectra were measured between 300 and $600 \mathrm{~nm}$. 
Excitation was at $295 \mathrm{~nm}$ through a slit width of $3 \mathrm{~nm}$ at $25^{\circ} \mathrm{C}$ and a scan speed of $100 \mathrm{~nm}$ per minute.

\section{Circular Dichroism}

Chiral organisation of the non-chiral fluorenyl group and tyrosine was determined by circular dichroism (CD). Initially a solution of Fmoc- $p$ Y was pipetted into the sample chamber of a quartz cell (path length $0.5 \mathrm{~mm}$, Hanna) and the full spectrum (190-350 nm with a bandwidth of $1 \mathrm{~nm}$ and a response time at 0.5 seconds) was measured at $20^{\circ} \mathrm{C}$, using a Jasco J810 Spectropolarimeter with a Forma Scientific water bath and temperature control. The photomultiplier tube voltage was measured at the same time to ensure reliable results providing the voltage remained below $500 \mathrm{~V} .{ }^{37}$ This data is provided for the individual spectra in the supplementary information. The cuvette was then cleaned with Decon, nitric acid, and then distilled water. AP was added to the solution of Fmoc- $p$ Y and thoroughly mixed before a sample was pipetted into the sample chamber. Spectra were obtained every 10 minutes for 6 hours on an interval scan setting to measure the changes during gelation. The focus of the investigation was the induced Fmoc-chirality which gives rise to a peak maximum at $307 \mathrm{~nm}$ and minimum at 316 $\mathrm{nm}$.

\section{Oscillatory Rheology}

Changes in materials mechanical properties over time were measured using a timed oscillatory study on a strain controlled rheometer (TA instrument AR-G2 machine with a peltier plate with automatic temperature control). A cone and plate geometry $\left(2^{\circ}, 20 \mathrm{~mm}\right.$ with a truncation distance of $56 \mu \mathrm{m}$ ) was used with a solvent trap to ensure the sample remained hydrated for the duration of the time course. The AP was added to the solution of Fmoc- $p \mathrm{Y}$ and 
thoroughly mixed before a sample was added to the peltier plate $\left(20^{\circ} \mathrm{C}\right)$. The sample was then tested every 30 seconds for 6 hours to measure the changes in the elastic modulus $\left(G^{\prime}\right)$, viscous modulus (G') and the ratio between the two, Tan $\delta$ at a strain of $0.1 \%$ and a frequency of $1 \mathrm{~Hz}$. To ensure the strain fell within the linear viscoelastic region once the timed study was finished an amplitude sweep was completed ensuring the results were a true reflection of changes in materials properties.

\section{Atomic Force Microscopy}

Round glass cover slips (Agar Scientific) were cleaned in ethanol and left to dry in a dust free environment. The solutions were prepared and a sample $(100 \mu \mathrm{l})$ was pipetted onto the slides and left for specific time periods. At the end of the time course, whether it remained a solution or had formed a hydrogel, the excess water was wicked away (Whatman 1 filter paper) and underwent a series of washes with filtered $(0.22 \mu \mathrm{m})$ HPLC grade water and wicked away. The number of washes was recorded and the glass slides were then left to dry fully in a dust free environment. The structures formed were imaged using a Veeco multimode AFM with an Escanner and a NanoScope IIIa controller using an Olympus tip in tapping mode. All images were taken at a nominal spring constant of $42 \mathrm{~N} / \mathrm{m}$ and the cantilever oscillation varied between 300 and $350 \mathrm{kHz}$ at a scan rate of $1.49 \mathrm{~Hz}$.

\section{Results and Discussion}

Previous studies have demonstrated the enzyme triggered self-assembly by Fmoc- $p \mathrm{Y}$ dephosphorylation, although the detailed self-assembly mechanism has yet to be investigated. The major difference in the assembly driving force between Fmoc- $p \mathrm{Y}$ and Fmoc-Y is the electrostatic repulsion of phosphate groups prior to biocatalytic conversion, which gives rise to 
clustering of fluorenyl groups and solvent exposure of the phosphates (Figure 1). Upon dephosphorylation, hydrophobic/ pi stacking effects take over as the main driving force to produce fibrils which may further be stabilised by H-bonding interactions.

We will firstly discuss the various self-assembly stages (Figure 1) for one enzyme concentration $\left(3.3 \times 10^{-2} \mathrm{mgs}\right.$ of protein in $1 \mathrm{ml}$ solution of $40 \mathrm{mM}$ Fmoc- $\left.p \mathrm{Y}\right)$. The enzyme concentrations are subsequently varied in the range $1.1 \times 10^{-3}$ to $0.11 \mathrm{mgs}$ of protein.

\section{Mechanism of phosphatase triggered self-assembly of Fmoc-Y}

HPLC analysis shows that, in the presence of $3.3 \times 10^{-2} \mathrm{mgs}$ protein, dephosphorylation is complete within five minutes (HPLC time courses are discussed in a later section). There is a significant lag time between enzymatic conversion and formation of a stable self-supporting hydrogel, in contrast to our previous study on Fmoc-FpY, ${ }^{34}$ where gelation was observed once the critical micelle concentration of the precursors had been reached. The gelation time at this enzyme concentration was two hours, determined initially by vial inversion and confirmed by oscillatory rheology (as discussed below). To determine the presence and nature of supramolecular structures formed during this time we utilised spectroscopy techniques, namely fluorescence spectroscopy and CD.

The fluorescence spectra of solutions of Fmoc- $p$ Y precursors and the hydrogel of FmocY revealed a number of distinct features (Figure S1 in Electronic Supplementary Information (ESI)). A first peak (I), centred at $320 \mathrm{~nm}$, is attributed to the free fluorenyl present in unassociated Fmoc- $p$ Y in solution. A second peak (II), appears as a shoulder between 350 and 370 $\mathrm{nm}$ and is thought to represent parallel organisation of fluorenyls in micelles or micellar aggregates, similar to observations for Fmoc-FpY in solution. ${ }^{11 \mathrm{a}}$ To confirm formation of 
micelles, fluorescence spectra were measured for a range of precursor concentrations and the CMC of Fmoc- $p \mathrm{Y}$ was estimated at $14 \mathrm{mM}$ (Figure S2). After formation of the Fmoc-Y hydrogel, these two peaks were displaced by a more intense peak centred at $325 \mathrm{~nm}$ (III), which suggests that the fibrillar fluorenyl environment is significantly different from that in the micellar phase, Figure 2.

Upon addition of AP we observe an immediate increase in the intensity of peak I and II reaching a maximum at 15 minutes. Peak II, which is associated with the parallel orientation of fluorenyls in micellar aggregates, remains present in the emission spectra until 2 hours after enzyme addition, Figure 2, despite the rapid dephosphorylation. In addition (as discussed later), the system remains CD silent, indicating that fluorenyls do not yet reorganise into the configuration associated with chiral fibres that are found upon gelation. These observations suggest that the dephosphorylated Fmoc-Y remains in a similar orientation for a period of time, subsequent to dephosphorylation. The meta-stable structures that are formed appear to involve a similar organisation of Fmoc-Y species compared to their Fmoc- $p$ Y precursors based on the emission spectra. However, they are clearly less quenched, suggesting a less densely packed organisation. This could be a result of the change in hydrophobic/philic balance rendering it less surfactant-like and more prone to unidirectional self-assembly and gelation. In the control experiment, a solution where no AP was added, there were no significant changes in the intensity of the emission spectra across the time course (Figure S3). The above contrasts our previous observations for Fmoc-FpY, where a significant fluorenyl rearrangement is evident once the CMC is reached. ${ }^{34}$ This transformation is probably favoured because of the formation of $\beta$-sheet structures in the previous system which is well known to facilitate fibre formation. Indeed, at lower concentrations (below $20 \mathrm{mM}$, note that gelation experiments were carried out at $40 \mathrm{mM}$ ), 
Fmoc-Y was found to adopt a micellar structure, with a CMC similar to that of Fmoc- $p \mathrm{Y}$ (Figure S4). This temporary enhancement in fluorescence emission is followed by a rapid decline in fluorenyl emission intensity between 15 and 30 minutes, Figure 2A, which marks the onset of fibre formation.

Supramolecular chirality of non-chiral fluorenyl groups has previously reported in gelphase systems and can be monitored by circular dichroism (CD). CD of the solution of Fmoc$p \mathrm{Y}$ and the hydrogel Fmoc-Y were initially investigated, Figure 3. While the precursor solution was CD silent, in the hydrogels two fluorenyl peaks were detected, the first centred at $303 \mathrm{~nm}$ $\left(\pi \rightarrow \pi^{*}\right.$ transition) and the second at $217 \mathrm{~nm}\left(\mathrm{n} \rightarrow \pi^{*}\right.$ transition). The latter will no longer be discussed due to the poor signal to noise ratio observed below $220 \mathrm{~nm}$ (Figure S5). Previous studies of Fmoc-Y peaks between 200-240 nm attributed to the chirality of the tyrosine component although in solution these are usually observed in the near UV region (250-300 $\mathrm{nm}){ }^{38-40}$ The peaks present in the aromatic region of the near UV may represent induced chirality of the tyrosine derivative and the Fmoc-group. ${ }^{21}$

We focused our investigation on the fluorenyl chirality, Figure 4a. In micellar solutions, no changes were detected in the control (no AP) during the 6-hour time course. On addition of the enzyme $\left(3.3 \times 10^{-2} \mathrm{mgs}\right.$ protein $)$ no changes were detected in the signal for two hours, as expected for the two-stage phosphorylated and de-phosphorylated micellar assemblies discussed above, Figure $\mathbf{4 b - d}$. It should be noted that the potential tyrosine interactions were not detected during the time course, comparing Figure 3 and 4 b-g.

After the first chiral structures were detected ( 2 hours) the signal reaches a plateau at 3 hours. The formation of chiral structures and gelation are closely linked as demonstrated by the time 
course rheological study, Figure 5. The time difference between gelation observed by rheology and the detection of the first chiral structure is unexpected and probably related to the different sample sizes used in each experiment. The sample size used in rheology is significantly larger than that for the $\mathrm{CD}$ and this difference in surface/volume can reasonably explain the delay observed in the latter.

There was a delay between dephosphorylation and the gelation point, indicated by a black arrow in Figure 5, which was shorter than expected (80 minutes compared to 2 hours observed by vial inversion). The initial gel point (black arrow) indicates a viscosity change, ${ }^{41}$ while eventually G' reaches a value that is over an order of magnitude higher than G,42 (grey arrow at 2 hours), indicating true gelation. Once the initial gelation point was reached a rapid increase in both moduli was observed, that reached a plateau by 3 hours. Although the CD signal reached a plateau within an hour, the network structure takes longer to stabilise due to the continued aggregation and entanglement of the fibres. The final moduli after six hours were $38 \mathrm{kPa}$ for G' and $1 \mathrm{kPa}$ for G'. On completion of the time course, an amplitude sweep was completed to ensure the strain used throughout the time course fell within the linear viscoelastic region (Figure S6).

Having investigated the molecular interactions and the changes in mechanical properties over the time course we moved onto investigating the formation of nanostructures using AFM at specific time points over the six hour time study, Figure 6. Prior to enzyme addition only the surface of the glass was observed for Fmoc- $p \mathrm{Y}, \mathrm{t}=0$ minutes, Figure 6.

Ten minutes after enzyme addition, where only an increase in intensity was detected by fluorescence spectroscopy, spherical aggregates were imaged. The spherical aggregates had an 
average width of $160 \pm 65 \mathrm{~nm}$ and an average height of $9 \pm 5 \mathrm{~nm}, \mathrm{n}=30$. The AP, on mica due to its regular topography, has previously been observed at $29 \pm 24 \mathrm{~nm}$ with an average height of $6 \pm 5 \mathrm{~nm}$ (Figure S7). Due to the significant differences in size and the absence of these aggregates at other time points these are not believed to be solely due to the AP. Spherical features could not be detected at earlier time points so there is a correlation with the observed enhancement in fluorescence emission, described earlier. Therefore, these results may suggest that initial micelles of Fmoc-Yp, upon losing their surface charge when dephosphorylated, become prone to aggregation which gives rise to formation of these structures that are now visible by AFM. Dynamic light scattering was completed on the solution before and after enzyme addition to confirm the formation of aggregates; however, it proved inconclusive. This was attributed to the number of different aggregates present in solution, AP, Fmoc-Y, and micelles of Fmoc-Y, and assembly of Fmoc-Y around AP, preventing accurate assessment by dynamic light scattering.

One hour after AP addition, there are no spherical aggregates observed, however an amorphous layer of material is observed covering the mica surface (Figure 6) which suggests the aggregates formed become larger and unstable prior to nucleation of nanofibres. Two hours after AP addition, fibres are observed forming a dense network. Although the network density prevented accurate sizing of fibres, there are differences observable by eye between the fibres and the networks formed across the time course. At 2 hours, the fibres appear thinner than the later time points when the fibres appear to bundle. The images obtained by AFM correlate well with the supramolecular changes observed by spectroscopy techniques and the mechanical properties over time. 


\section{Stabilisation of the alkaline phosphatase}

Given the unexpected enhanced fluorescence and the observation of spherical objects by AFM at approximately 10-30 minutes we investigated the early stages of enzyme triggered selfassembly in more details by varying the AP concentration to determine whether the proposed self-assembly process holds true for all enzyme concentrations. The volume of enzyme buffered solution added to the precursor solution (Fmoc- $p \mathrm{Y}$ at $40 \mathrm{mM}$ ) remained constant at $100 \mu \mathrm{l}$ although the activity varied (three additional concentrations were investigated $1.1 \times 10^{-3}, 1.1 \mathrm{x}$ $10^{-2}$ and $0.11 \mathrm{mgs}$ protein).

We firstly investigated the rate of conversion via HPLC which, as expected, demonstrated a dependence on AP concentration ${ }^{6}$. At the higher concentrations of AP $\left(3.3 \times 10^{-2}\right.$ and $0.11 \mathrm{mgs}$ protein) conversion was completed within the first five minutes although there were no significant differences in their gelation times (Figure $7 \mathbf{c}$ and d). The conversion rate at these concentrations is estimated to be at least $0.76 \pm 0.004 \mathrm{mM} \mathrm{min}^{-1} \mathrm{mg}$ of protein ${ }^{-1}$.

At the lowest concentration of AP $\left(1.1 \times 10^{-3} \mathrm{mgs}\right.$ protein $)$ the conversion rate to Fmoc-Y, is discontinuous suggesting a change in enzyme activity during the course of the reaction, Figure 7a. For example, during the initial 20 minutes after AP addition, the conversion rate is $3 . \pm 0.25$ $x 10^{-2} \mathrm{mM} \mathrm{min}^{-1} \mathrm{mg}$ of protein ${ }^{-1}$. An increase in conversion rate is detected between 20 mins and 2 hours, an enhanced conversion of $7.3 \mathrm{mM} \pm 0.6 \times 10^{-2} \mathrm{mM} \mathrm{min}^{-1} \mathrm{mg}$ of protein ${ }^{-1}$ ( $\mathrm{p}=0.01$ two tailed t-test assuming unequal variations), that further increases between 2 and 4 hours to 0.10 $\mathrm{mM} \pm 0.004 \mathrm{mM} \mathrm{min}^{-1} \mathrm{mg}$ of protein ${ }^{-1}(\mathrm{p}=0.006)$. This suggests that during the course of the reaction there is a change to the AP that triggers an enhancement of its activity. This is also 
clearly observed at $1.1 \times 10^{-2} \mathrm{mgs}$ protein as a discontinuous rate profile was also measured, Figure $7 \mathbf{b}$.

For this higher enzyme concentration, during the first ten minutes, the conversion rate is similar to that at the lower concentration at 3.6 $\pm 0.1 \times 10^{-2} \mathrm{mM} \mathrm{min}^{-1} \mathrm{mg}$ of protein ${ }^{-1}$. Between 10 minutes and 30 minutes after enzyme addition the rate increases to $6.9 \pm 0.2 \times 10^{-2} \mathrm{mM} \mathrm{min}^{-1} \mathrm{mg}$ of $\operatorname{protein}^{-1}(\mathrm{p}=0.0003)$ and reaches its maximum conversion rate of $0.13 \pm 0.011 \mathrm{mM} \mathrm{min}^{-1} \mathrm{mg}$ of protein $^{-1}$ between 30 minutes and an hour after enzyme addition $(p=0.01)$. At this enzyme concentration, we observe that this enhanced activity is only a temporary effect as demonstrated by the decrease in conversion rate after this time although the reaction has yet to reach completion. Between one hour and two hours the conversion rate had decreased to $6.1 \pm 0.4 \times 10^{-2}$ $\mathrm{mM} \mathrm{min}^{-1} \mathrm{mg}$ of protein ${ }^{-1}$ and further still between 2 and 4 hours to $2.4 \pm 0.3 \times 10^{-2} \mathrm{mM} \mathrm{min}^{-1} \mathrm{mg}$ of $_{\operatorname{protein}^{-1}}(\mathrm{p}=0.01$ and 0.0001 respectively).

We postulate that the changes in enzymatic activity observed may be due to the selfassembly of Fmoc-Y around the AP which may have a stabilising effect on its activity due to its surfactant like properties. A previous study by Wang et al. has suggested that gelation of Fmoc$\mathrm{Y}$, triggered by acid phosphatase, leads to stabilisation of the enzyme and enhanced activity in a range of organic solvents when compared to enzyme in the absence of gelator. ${ }^{17}$ Therefore, it seems reasonable to suggest that the presence of Fmoc-Y may lead to stabilisation of the AP (especially as it is a membrane protein which may benefit from a more hydrophobic environment), leading to enhancement of its activity prior to gelation. To confirm this we moved onto fluorescence spectroscopy to determine whether the changes in intensity relate to the discontinuous rate profile of AP activity observed previously. 
Across the AP concentration range studied here, changes in the intensity of the fluorenyl spectra were detected and occurred in a time and concentration dependant manner. In the presence of $1.1 \times 10^{-3} \mathrm{mgs}$ protein, no significant changes in the fluorescence spectra intensity were observed until 2 to 4 hours after enzyme addition when a slight increase is observed (Figure 8a, d and e). On increasing the enzyme concentration to $1.1 \times 10^{-2} \mathrm{mgs}$ protein, increments in intensity are detected to similar levels to $3.3 \times 10^{-2} \mathrm{mgs}$ protein (Figure 2a) although over a longer time course, Figure $\mathbf{8 b}$. Initially, at this AP concentration there is a slight decrease in intensity where it remains for 15 minutes after AP addition. The intensity then increases, reaching its maximum by 1 hour which is thought to represent a temporary environment as demonstrated by the subsequent loss in intensity. The initial increase in the conversion rate at 20 minutes is then matched by a rise in fluorenyl intensity. The maximum conversion rate at this concentration $\left(0.13 \mathrm{mM} \mathrm{min}^{-1} \mathrm{mg}\right.$ of protein $\left.{ }^{-1}\right)$ correlates with the highest fluorenyl intensity reading during the time course for this concentration. The decrease in fluorescence intensity after this time correlates with a decrease in average AP activity at 2 hours. Therefore, it is suggested that the changes in the fluorenyl environment are directly related to the changes in enzymatic rate. Although we have previously demonstrated the changes in fluorescence spectra intensity for $3.3 \times 10^{-2} \mathrm{mgs}$ protein, Figure 2, it is not possible to link the changes in fluorescence intensity with changes in enzymatic rate due to the rapid conversion to Fmoc-Y. At $0.11 \mathrm{mgs}$ protein an increase in fluorescence intensity is not detected until one hour after AP addition, Figure 8C, where enzymatic conversion is thought to outpace supramolecular formation. 


\section{Conclusions}

A range of techniques were utilised to investigate the AP triggered self-assembly process of Fmoc-Y. We have demonstrated that within these conditions (40mM Fmoc- $p \mathrm{Y}, \mathrm{pH} 7,0.15 \mathrm{M})$ a three-stage SA process of Fmoc-Y ocurs on addition of AP. Previous studies have demonstrated incorporation of enzymes (acid phosphatase) into fibres formed by the selfassembly of Fmoc-Y on gelation. ${ }^{17}$ We herein provide evidence that enzymatic dephosphorylation results in formation of temporary aggregates formed prior to fibre formation and gelation. Formation of these aggregates was evidenced by observed changes in fluorescence intensity combined with a lack of CD signal typical for relatively disorganised aggregates, and the formation of spherical structures observed by AFM. It is proposed that the removal of surface charge upon dephosphorylation gives rise to enhanced aggregation of Fmoc-Y compared to Fmoc-Yp. An enhanced enzymatic conversion rate was observed upon formation of these aggregates, evidenced by a correlation between enzymatic conversion rate (at $1.1 \times 10^{-3}$ and $1.1 \mathrm{x}$ $10^{-2}$ mgs protein) and fluorescence enhancement. It is suggested that the Fmoc-Y is surrounding the hydrophobic regions of the AP membrane protein triggering the changes in fluorescence intensity. The changes in conversion rate could indicate that this enhances the AP activity through stabilisation although further work is required to prove this.

The formation of chiral structures and gelation were closely linked at intermediate enzyme concentration. The enzymatic reaction rate was shown to dictate the hydrogels' mechanical properties similar to rate dependant mechanical properties observed for other systems, such as $\beta$-hairpin forming peptides. ${ }^{43}$ These results illustrate significant differences between $\mathrm{pH}$ and enzyme triggered self-assembly processes and provides further insight into biocatalytic self-assembly. 


\section{Acknowledgment}

Authors acknowledge EPSRC, HFSP, ERC (Starting Grant EMERgE), FP7 Marie Curie Actions

of the European Commission, via the initial training network ReAd (Contract No. 289723) and

Leverhulme Trust (Leadership Award) (U.K.) for funding.

\section{Notes and references}

${ }^{a}$ School of Materials, The University of Manchester, Grosvenor Street, Manchester M1 7HS, United Kingdom

${ }^{b}$ WestCHEM, University of Strathclyde, Department of Pure and Applied Chemistry, Thomas Graham Building, 295 Cathedral Street, Glasgow, UK G1 1XL.E-mail: rein.ulijn@strath.ac.uk

${ }^{c}$ BioAFM Facility, Faculty of Medical and Human Sciences, The University of Manchester, Manchester, UK

1. X. Zhao, F. Pan, H. Xu, M. Yaseen, H. Shan, C. A. Hauser, S. Zhang and J. R. Lu, Chemical Society Reviews, 2010, 39, 3480-3498.

2. L. C. Palmer and S. I. Stupp, Accounts of chemical research, 2008, 41, 1674-1684.

3. M. Zelzer, S. J. Todd, A. R. Hirst, T. O. McDonald and R. V. Ulijn, Biomaterials Science, 2013, 1, 11-39.

4. S. Mann, Angewandte Chemie International Edition, 2008, 47, 5306-5320.

5. Y. Gao, J. Shi, D. Yuan and B. Xu, Nat Commun, 2012, 3, 1033.

6. D. W. Löwik, E. Leunissen, M. Van den Heuvel, M. Hansen and J. C. van Hest, Chemical Society Reviews, 2010, 39, 3394-3412.

7. R. J. Mart, R. D. Osborne, M. M. Stevens and R. V. Ulijn, Soft Matter, 2006, 2, 822-835.

8. J. Raeburn, A. Zamith Cardoso and D. J. Adams, Chemical Society Reviews, 2013.

9. C. B. Minkenberg, B. Homan, J. Boekhoven, B. Norder, G. J. M. Koper, R. Eelkema and J. H. van Esch, Langmuir, 2012, 28, 13570.

10. C. B. Minkenberg, L. Florusse, R. Eelkema, G. J. M. Koper and J. H. van Esch, Journal of the American Chemical Society, 2009, 131, 11274-11275.

11. Z. Yang, G. Liang and B. Xu, Accounts of chemical research, 2008, 41, 315-326.

12. Z. Yang, H. Gu, D. Fu, P. Gao, J. K. Lam and B. Xu, Advanced Materials, 2004, 16, 1440-1444.

13. S. Winkler, D. Wilson and D. Kaplan, Biochemistry, 2000, 39, 12739-12746.

14. C. Wang, Q. Chen, Z. Wang and X. Zhang, Angewandte Chemie, 2010, 122, 8794-8797.

15. S. Toledano, R. J. Williams, V. Jayawarna and R. V. Ulijn, Journal of the American Chemical Society, 2006, 128, 1070-1071.

16. Z. A. Schnepp, R. Gonzalez-McQuire and S. Mann, Advanced Materials, 2006, 18, 1869-1872.

17. W. Wang, Z. Yang, S. Patanavanich, B. Xu and Y. Chau, Soft Matter, 2008, 4, 1617-1620.

18. B. Xu, Langmuir, 2009, 25, 8375-8377.

19. Z. Yang, K. Xu, Z. Guo, Z. Guo and B. Xu, Advanced Materials, 2007, 19, 3152-3156.

20. Z. Yang, G. Liang, Z. Guo and B. Xu, Angewandte Chemie International Edition, 2007, 46, 82168219. 
21. A. R. Hirst, S. Roy, M. Arora, A. K. Das, N. Hodson, P. Murray, S. Marshall, N. Javid, J. Sefcik, J. Boekhoven, J. H. van Esch, S. Santabarbara, N. T. Hunt and R. V. Ulijn, Nat Chem, 2010, 2, 10891094.

22. R. J. Williams, A. M. Smith, R. Collins, N. Hodson, A. K. Das and R. V. Ulijn, Nature nanotechnology, 2008, 4, 19-24.

23. A. K. Das, A. R. Hirst and R. V. Ulijn, Faraday discussions, 2009, 143, 293-303.

24. S. K. M. Nalluri and R. V. Ulijn, Chemical Science, 2013, DOI: 10.1039/C3SC51036K.

25. R. Orbach, L. Adler-Abramovich, S. Zigerson, I. Mironi-Harpaz, D. Seliktar and E. Gazit, Biomacromolecules, 2009, 10, 2646-2651.

26. M. Ma, Y. Kuang, Y. Gao, Y. Zhang, P. Gao and B. Xu, Journal of the American Chemical Society, 2010, 132, 2719-2728.

27. G. Cheng, V. Castelletto, C. Moulton, G. Newby and I. Hamley, Langmuir, 2010, 26, 4990-4998.

28. A. M. Smith, R. J. Williams, C. Tang, P. Coppo, R. F. Collins, M. L. Turner, A. Saiani and R. V. Ulijn, Advanced Materials, 2008, 20, 37-41.

29. B. Adhikari and A. Banerjee, Chemistry-A European Journal, 2010, 16, 13698-13705.

30. R. Huang, W. Qi, R. Su, J. Zhao and Z. He, Soft Matter, 2011, 7, 6418-6421.

31. L. Chen, K. Morris, A. Laybourn, D. Elias, M. R. Hicks, A. Rodger, L. Serpell and D. J. Adams, Langmuir, 2009, 26, 5232-5242.

32. D. J. Adams and P. D. Topham, Soft Matter, 2010, 6, 3707-3721.

33. C. Tang, A. M. Smith, R. F. Collins, R. V. Ulijn and A. Saiani, Langmuir, 2009, 25, 9447-9453.

34. J. W. Sadownik, J. Leckie and R. V. Ulijn, Chemical Communications, 2011, 47, 728-730.

35. D. Koda, T. Maruyama, N. Minakuchi, K. Nakashima and M. Goto, Chem. Commun., 2010, 46, 979-981.

36. K. Thornton, A. M. Smith, C. L. R. Merry and R. V. Ulijn, Biochemical Society Transactions, 2009, 37, 660 .

37. N. J. Greenfield, Nature protocols, 2007, 1, 2876-2890.

38. Z. Yang and B. Xu, Chemical Communications, 2004, 2424-2425.

39. A. Koslowski, N. Sreerama and R. Woody, Circular Dichroism: Principles and Applications, 2nd ed. N. Berova, K. Nakanishi, and RW Woody, editors. Wiley-VCH Press, New York, 2000, 55-95.

40. N. Sreerama and R. Woody, Circular dichroism: Principles and applications, 2000, 2, 601-620.

41. J. W. Goodwin and R. W. Hughes, Rheology for chemists: an introduction, Royal Society of Chemistry, 2008.

42. C. Yan and D. J. Pochan, Chemical Society Reviews, 2010, 39, 3528-3540.

43. L. Haines-Butterick, K. Rajagopal, M. Branco, D. Salick, R. Rughani, M. Pilarz, M. S. Lamm, D. J. Pochan and J. P. Schneider, Proceedings of the National Academy of Sciences, 2007, 104, 77917796. 


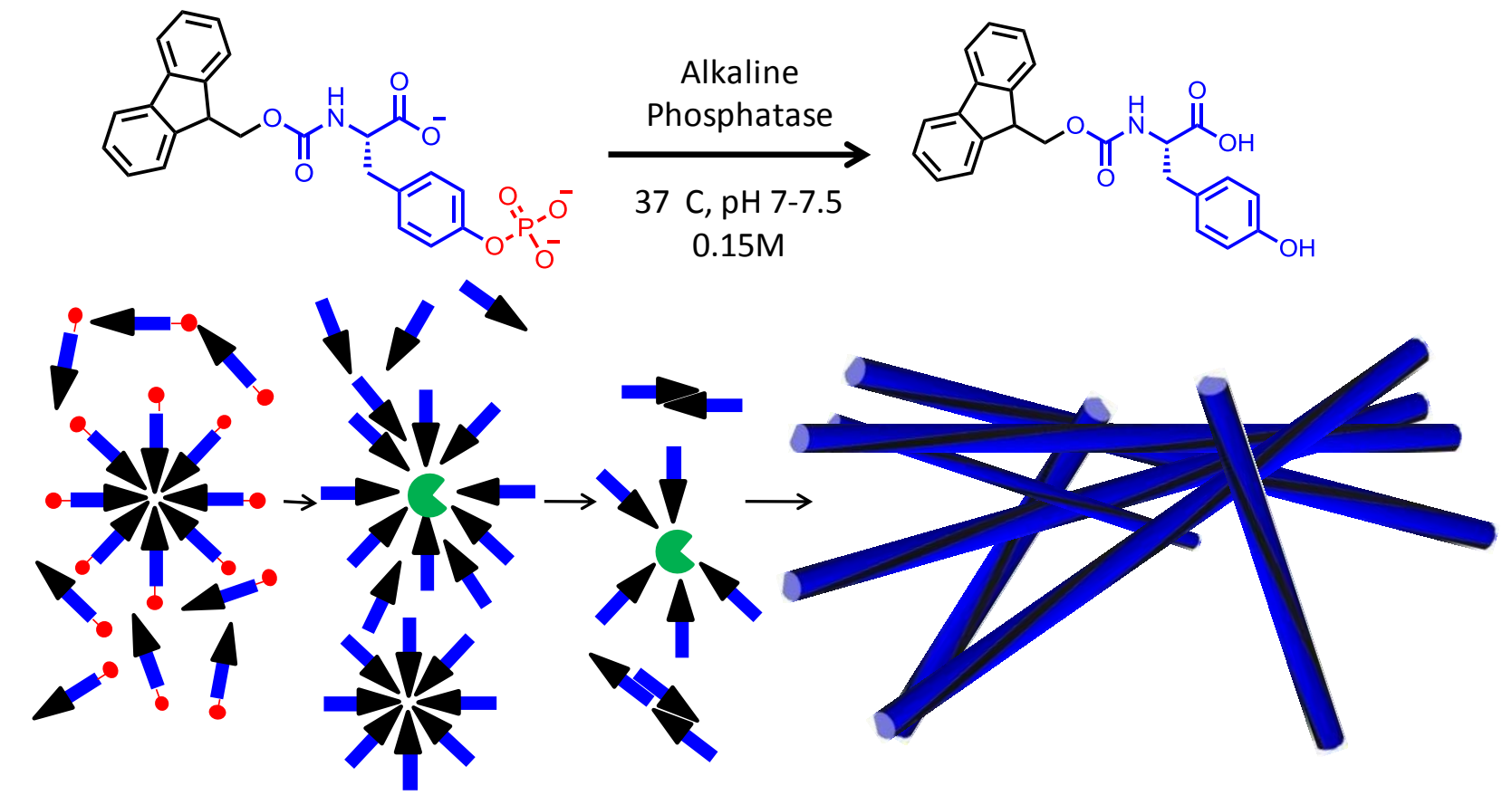

Figure 1. The chemical structures of the non-assembling precursor Fmoc-tyrosine (phosphate) (Fmoc- $p \mathrm{Y}$ ) and the gelator FmocY produced via the catalytic action of AP (a) A proposed schematic of the biocatalytic supramolecular transformation (b) The proposed changes that occur on AP triggered SA of Fmoc-Y-OH. 

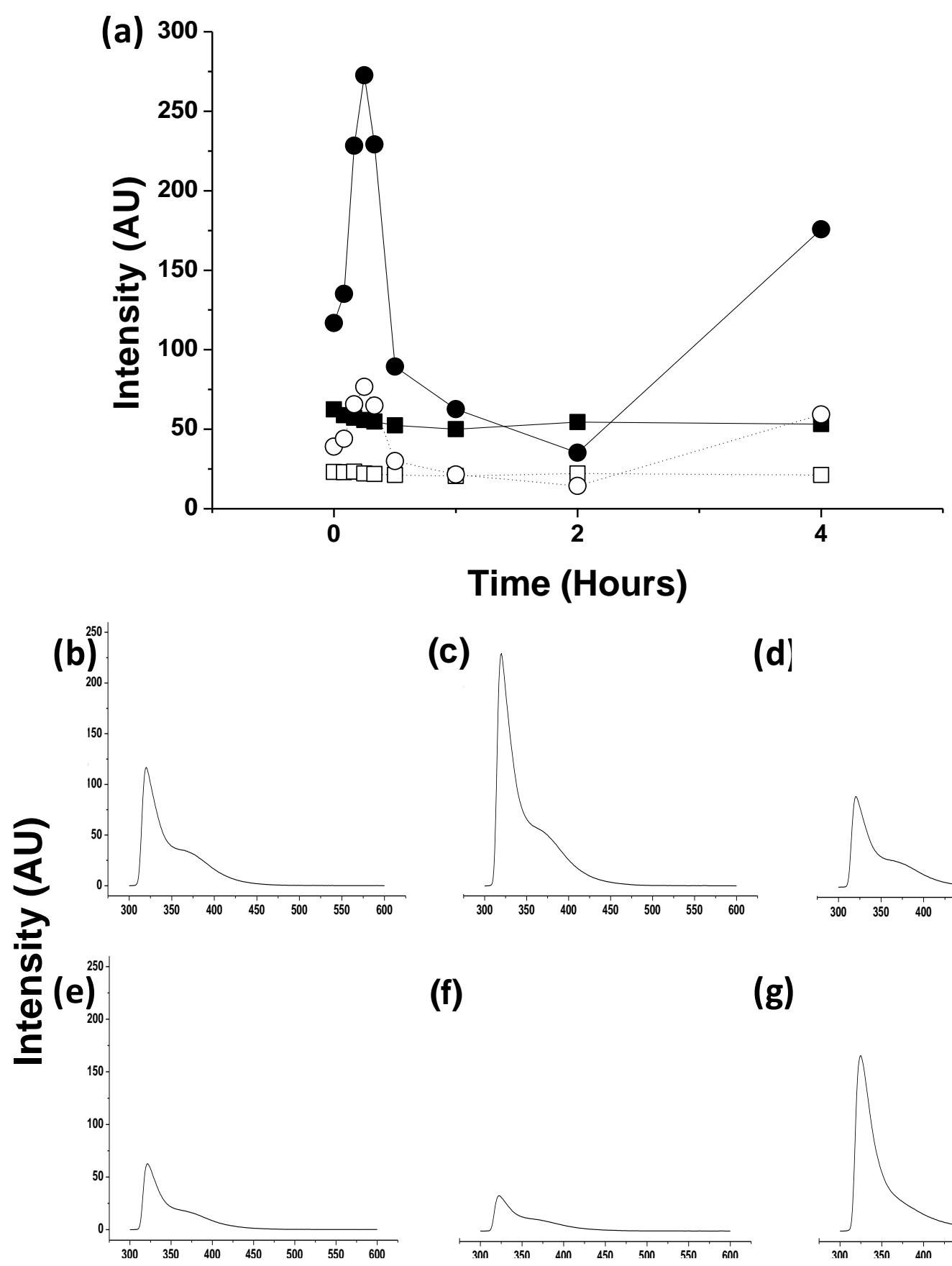

(c)

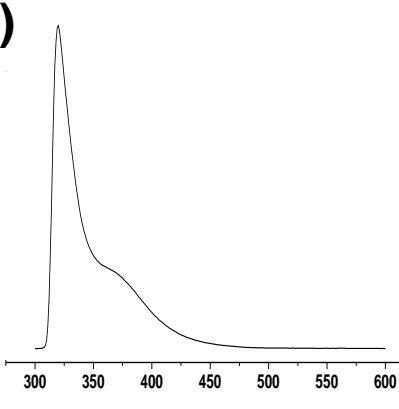

(d)

(f)

(g)
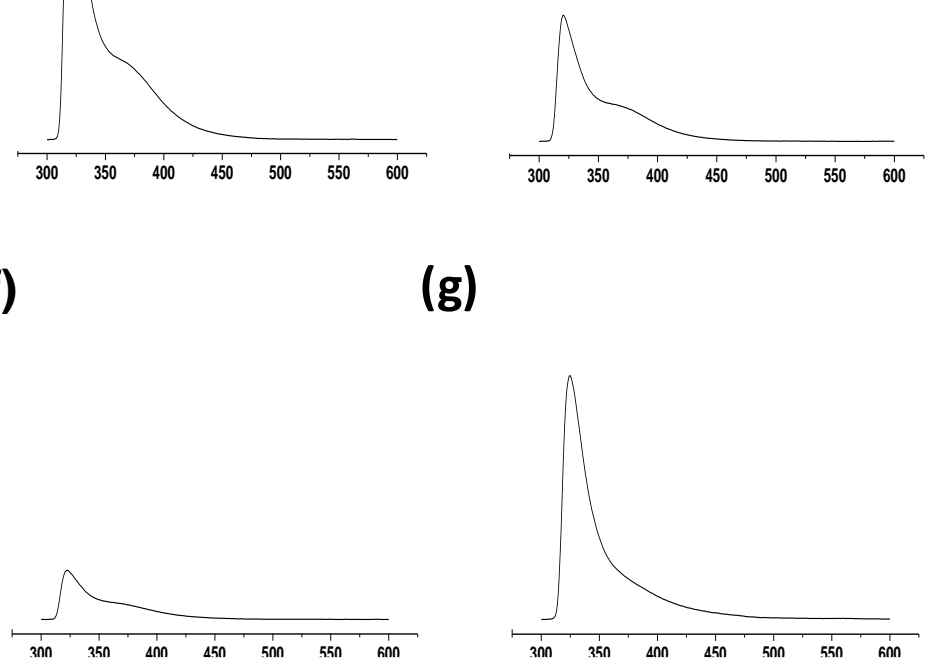

Wavelength (nm)

Figure 2. The changes in the intensity of the fluorescence spectra of Fmoc- $p \mathrm{Y}(40 \mathrm{mM})$ upon addition of $\mathrm{AP}$ at $3.3 \times 10^{-2} \mathrm{mgs}$ protein (circles) and in the absence of enzyme (squares) of the peak centred at $320 \mathrm{~nm}$ ( $\square$ and $\bullet$ ) and the peak at $375 \mathrm{~nm}(\square$ and ○) after excitation at $295 \mathrm{~nm}$. The individual emission spectra from specific time points are also given to show the spectra before enzyme addition (B) and the following time points after the addition of AP 10 mins (C), 30 mins (D), 1 hour (E), 2 hours (F) and 4 hours (G). $\lambda \operatorname{exc}=295 \mathrm{~nm}$. 


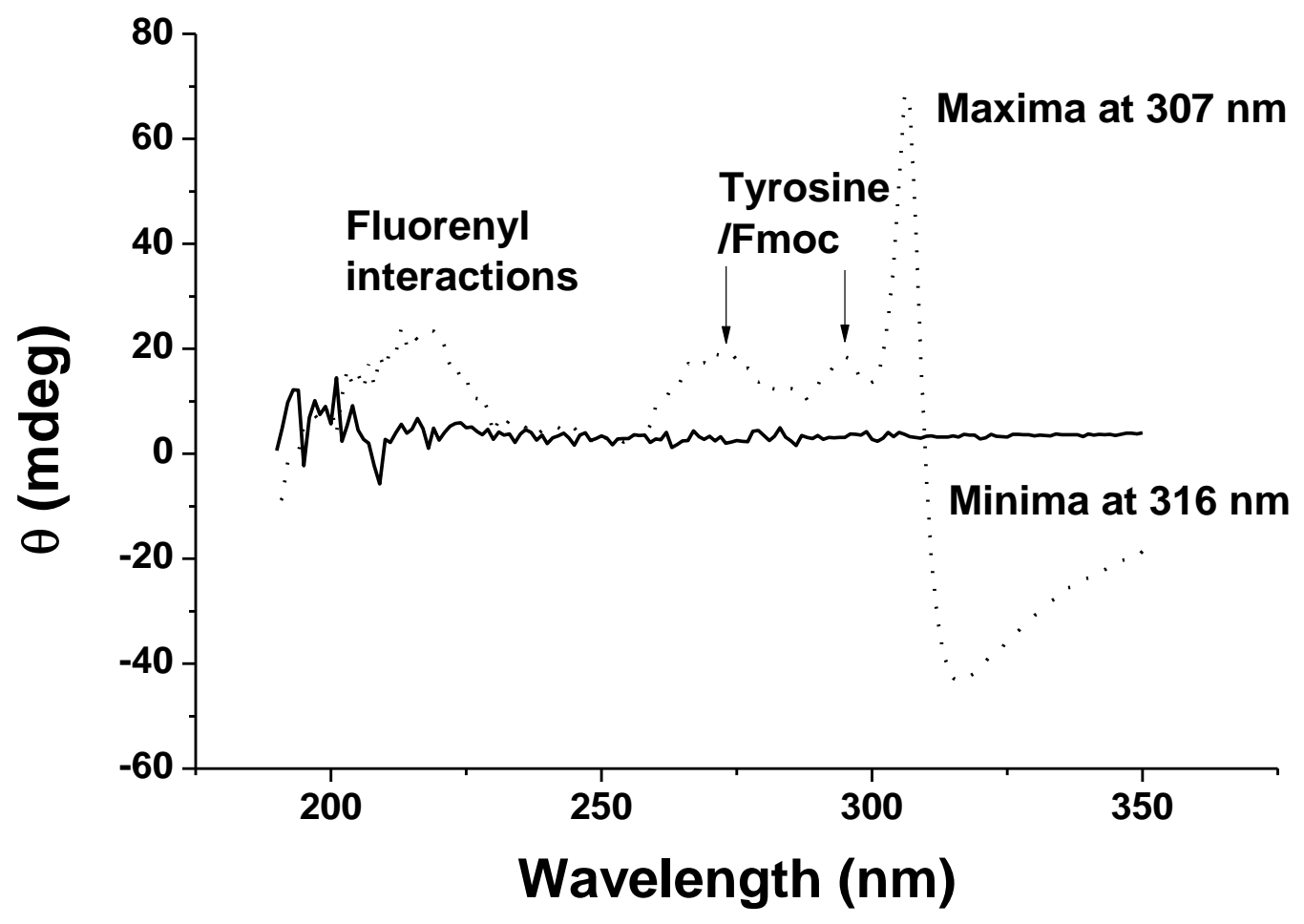

Figure 3. $\mathrm{CD}$ spectra of the solution of Fmoc- $p \mathrm{Y}$ (black line) and the hydrogel formed on enzyme addition (dotted line) at $3.3 \mathrm{x}$ $10^{-2}$ mgs protein AP. 


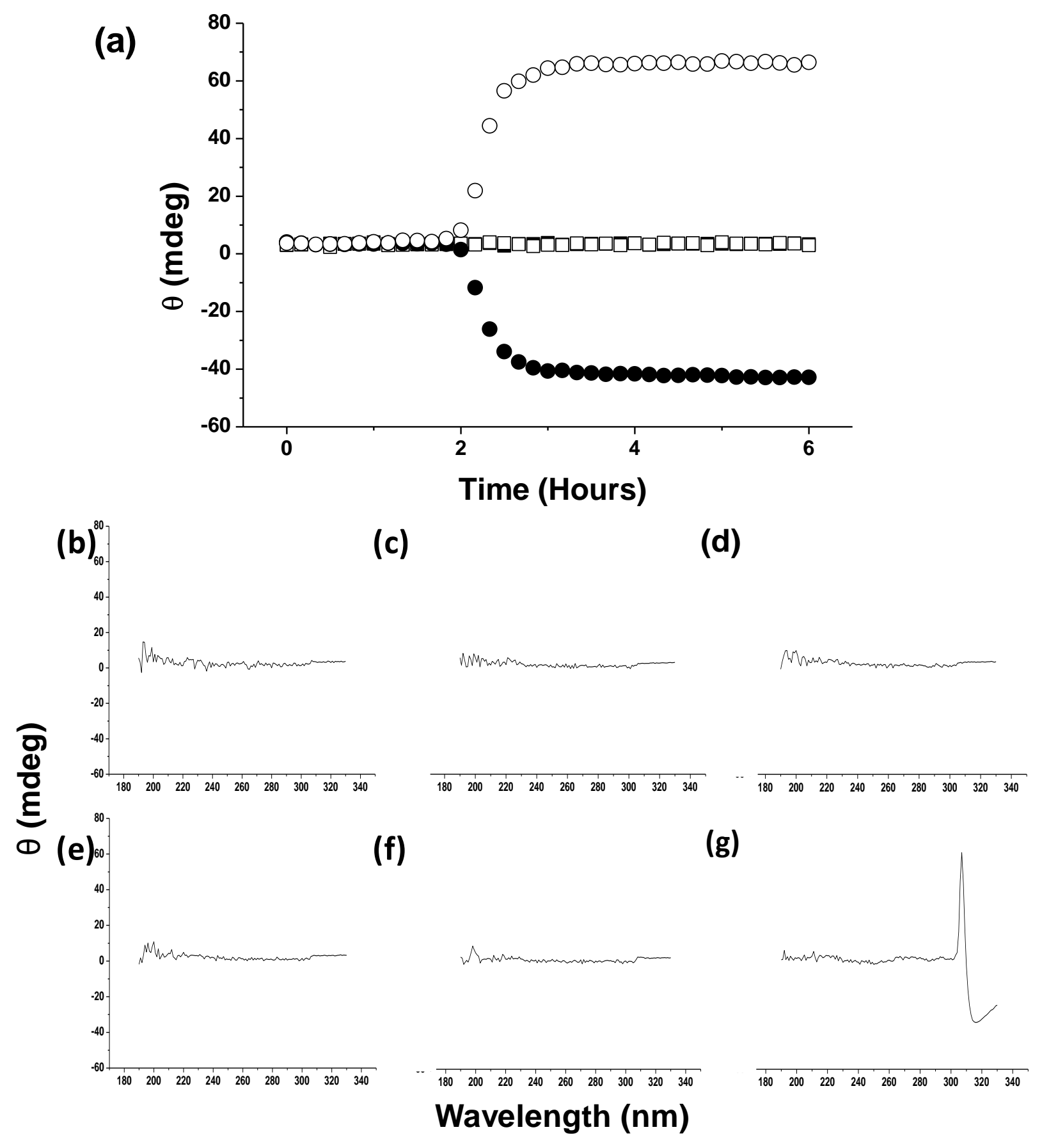

Figure 4. The changes in the spectra detected through circular dichroism of Fmoc- $p \mathrm{Y}(40 \mathrm{mM})$ on addition of $\mathrm{AP}$ at $3.3 \times 10^{-2}$ mgs protein (circles) and in the absence of enzyme (squares) of the peak maximum at $307 \mathrm{~nm}$ ( $\boldsymbol{\square}$ and $\bullet$ ) and the peak minimum at $316 \mathrm{~nm}(\square$ and $\circ)$. The individual emission spectra from specific time points are also given to show the spectra before enzyme addition (B) and the following time points after the addition of AP 10 mins (C), 30 mins (D), 1 hour (E), 2 hours (F) and 4 hours (G). The photomultiplier tube voltage for the individual spectra is supplied in Figure S5. 


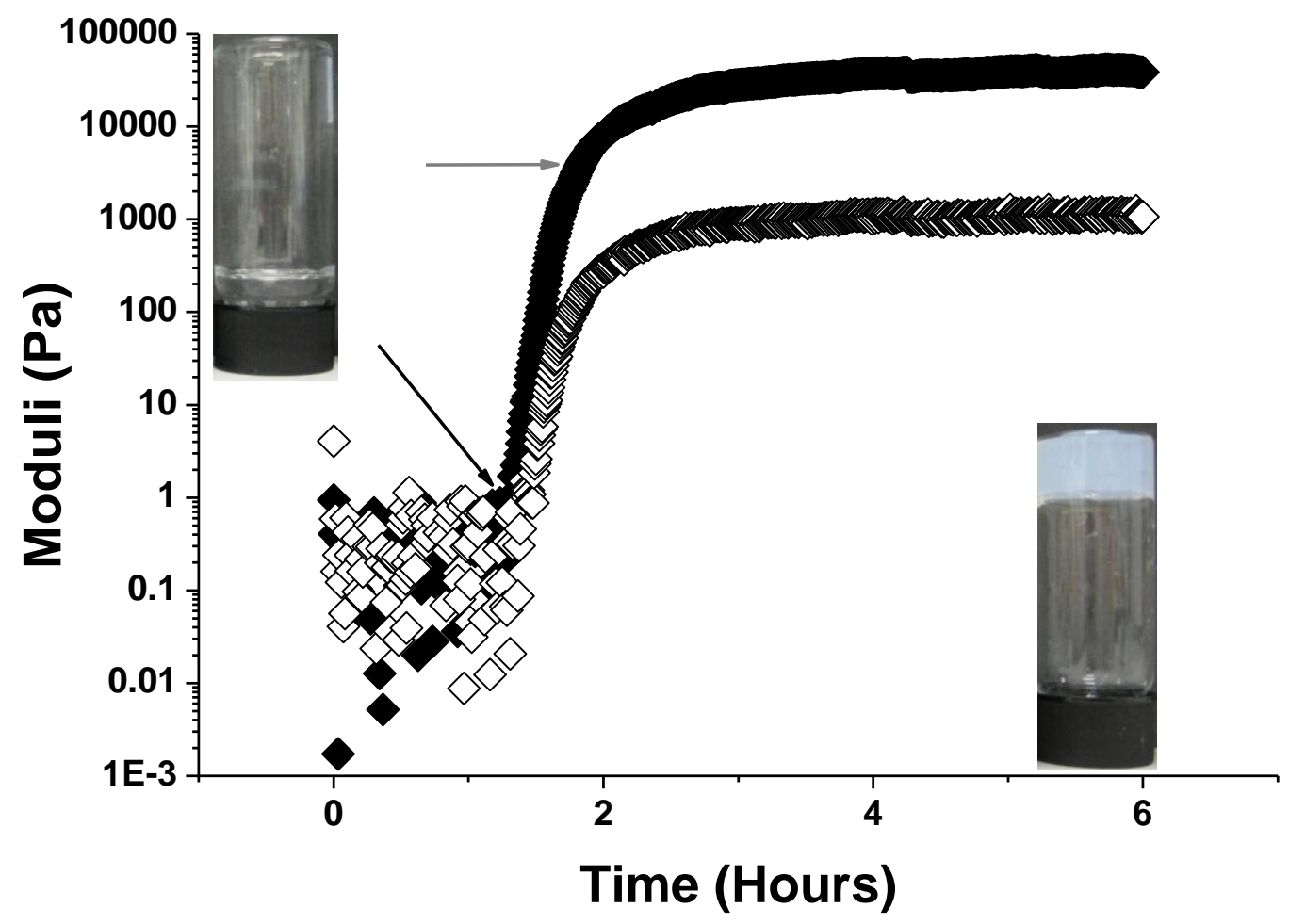

Figure 5. The changes in moduli detected through a timed oscillatory study on addition of AP (at $3.3 \times 10^{-2} \mathrm{mgs}$ protein) to a solution of Fmoc- $p \mathrm{Y}(40 \mathrm{mM})$. The black arrow indicated the point where the elastic modulus (black triangle) exceeds the viscous modulus (white triangle) indicating a viscosity change. The grey arrow indicates where the elastic modulus is an order of magnitude greater than that of the viscous modulus indicating the point where a stable self-supporting hydrogel has formed. 


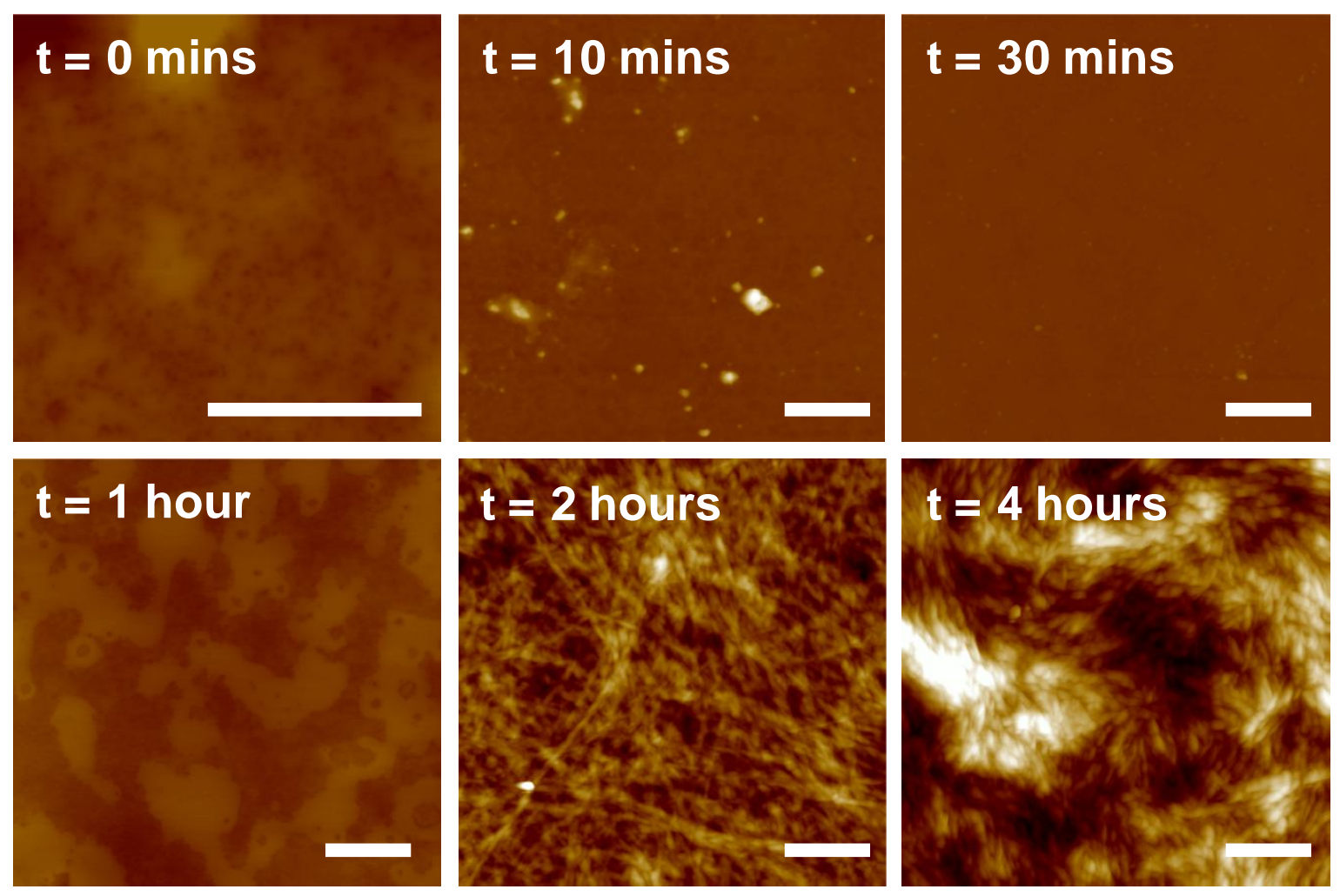

Figure 6. AFM images of selected time points of the fibres and structures formed on addition of AP ( $3.3 \times 10^{-2} \mathrm{mgs}$ protein) to Fmoc- $p \mathrm{Y}(40 \mathrm{mM})$. Scale bar $=1 \mu \mathrm{m}$. 


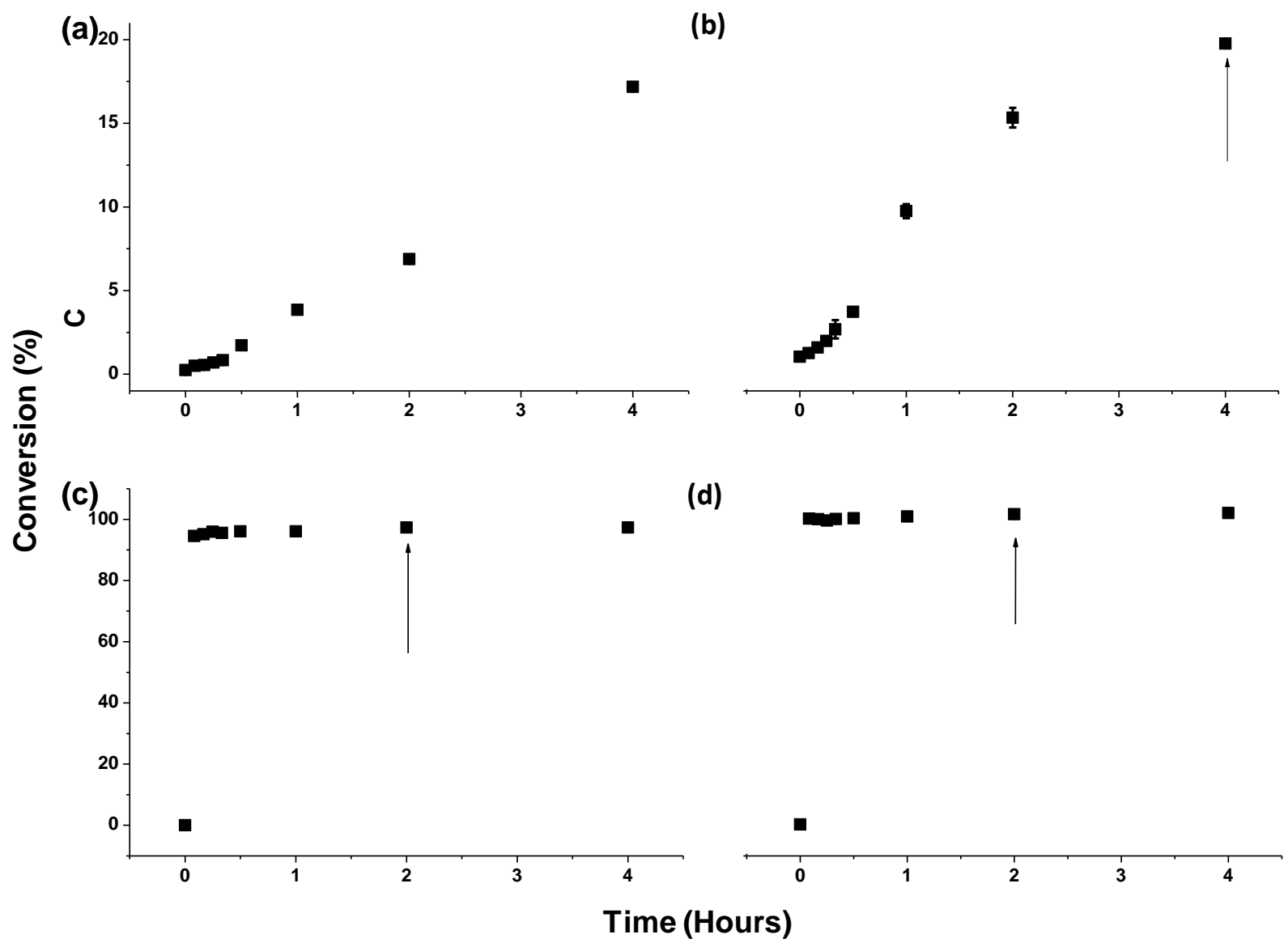

Figure 7. Enzymatic conversion of Fmoc- $p \mathrm{Y}(40 \mathrm{mM})$ to Fmoc-Y by AP at $1.1 \times 10^{-3}$ (a), $1.1 \times 10^{-2}$ (b), and $3.3 \times 10^{-2}$ (c) and $0.11 \mathrm{mgs}(\mathrm{d})$ protein as determined by reverse phase HPLC (Arrows indicate gel formation point). 

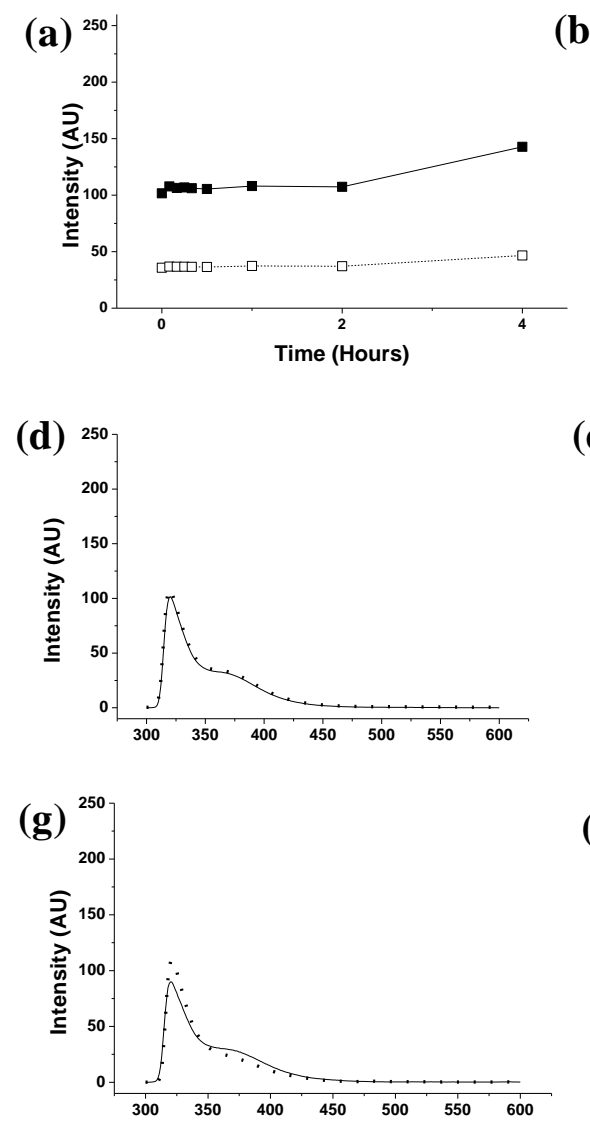

(b)

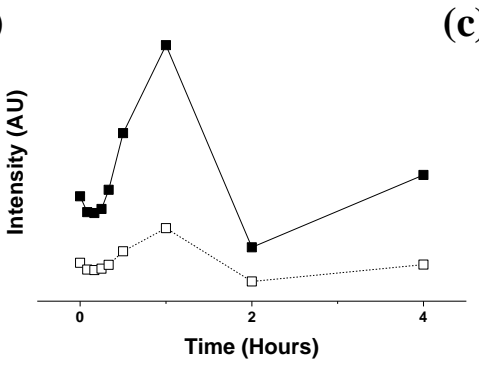

(e)

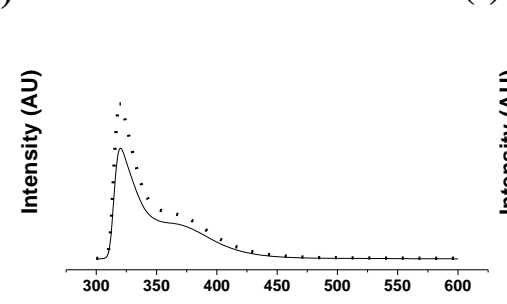

(h)

\section{Wavelength (nm)}

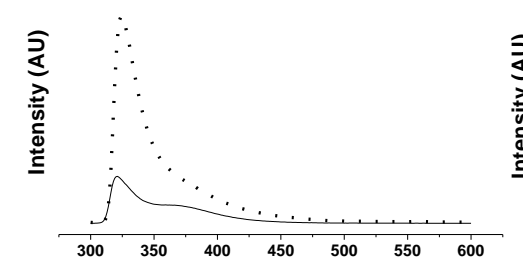

(c)

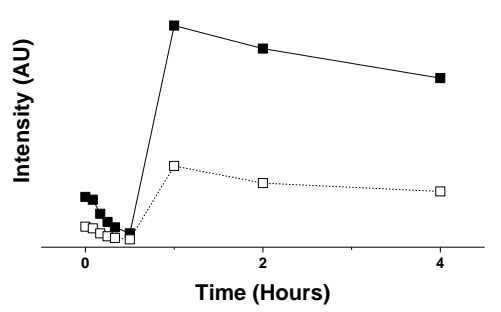

(f)

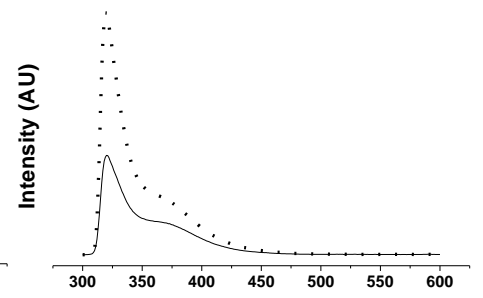

(i)

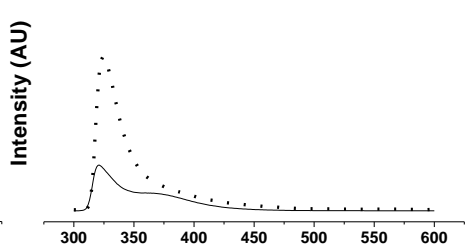

\section{Wavelength $(\mathbf{n m})$}

Figure 8. The changes in the intensity of the fluorescence spectra of Fmoc- $p$ Y (40 mM) on addition of AP at $1.1 \times 10^{-3}$ (a), $1.1 \times$ $10^{-2}$ (b) and $0.11 \mathrm{mgs}$ protein (c) of the peak centred at $320 \mathrm{~nm}$ ( $\square$ and $\bullet$ ) and the peak at $375 \mathrm{~nm}(\square$ and $\circ$ ) after excitation at $295 \mathrm{~nm}$. The individual emission spectra showing the changes prior to enzyme addition (solid black line) and either an hour after enzyme addition (dotted line in $\mathrm{d}, \mathrm{f}$ and $\mathrm{h}$ ) or four hours after enzyme addition (dotted line in $\mathrm{e}, \mathrm{g}$ and $\mathrm{i}$ ) for $1.1 \mathrm{x} 10^{-3}$ (d-e), $1.1 \mathrm{x}$ $10^{-2}$ (f-g) and $0.11 \mathrm{mgs}$ protein $(\mathrm{h}-\mathrm{i})$. 


\section{Supplementary Information}

\section{Mechanistic Insights into Phosphatase Triggered Self-Assembly Including Enhancement of Biocatalytic Conversion Rate}

Kate Thornton, Yousef M. Abul-Haija, Nigel Hodson and Rein V. Ulijn

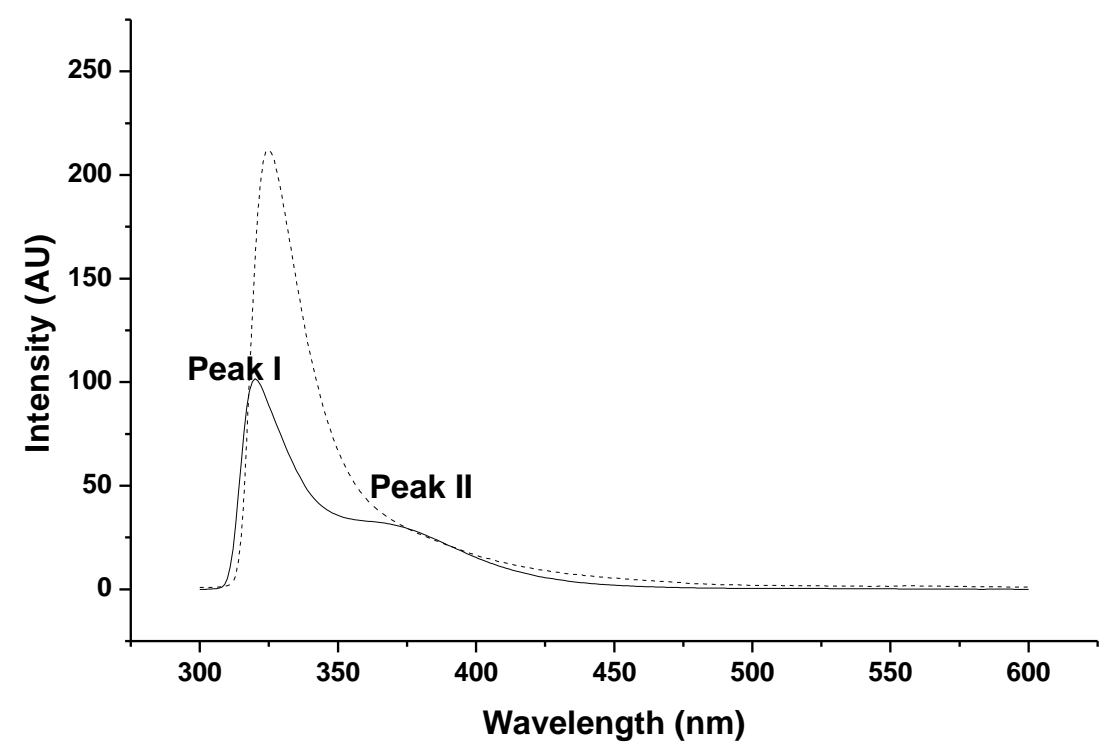

Figure S1. The fluorescence emission spectra after $\lambda_{\mathrm{exc}} 295 \mathrm{~nm}$ of the solution of Fmoc- $p \mathrm{Y}$ (40mM solid black line) and the hydrogels of Fmoc-Y-OH formed by AP trigger at $3.3 \times 10^{-2} \mathrm{mgs}$ protein (also $40 \mathrm{mM}$ dotted line) with the individual peaks labelled. 


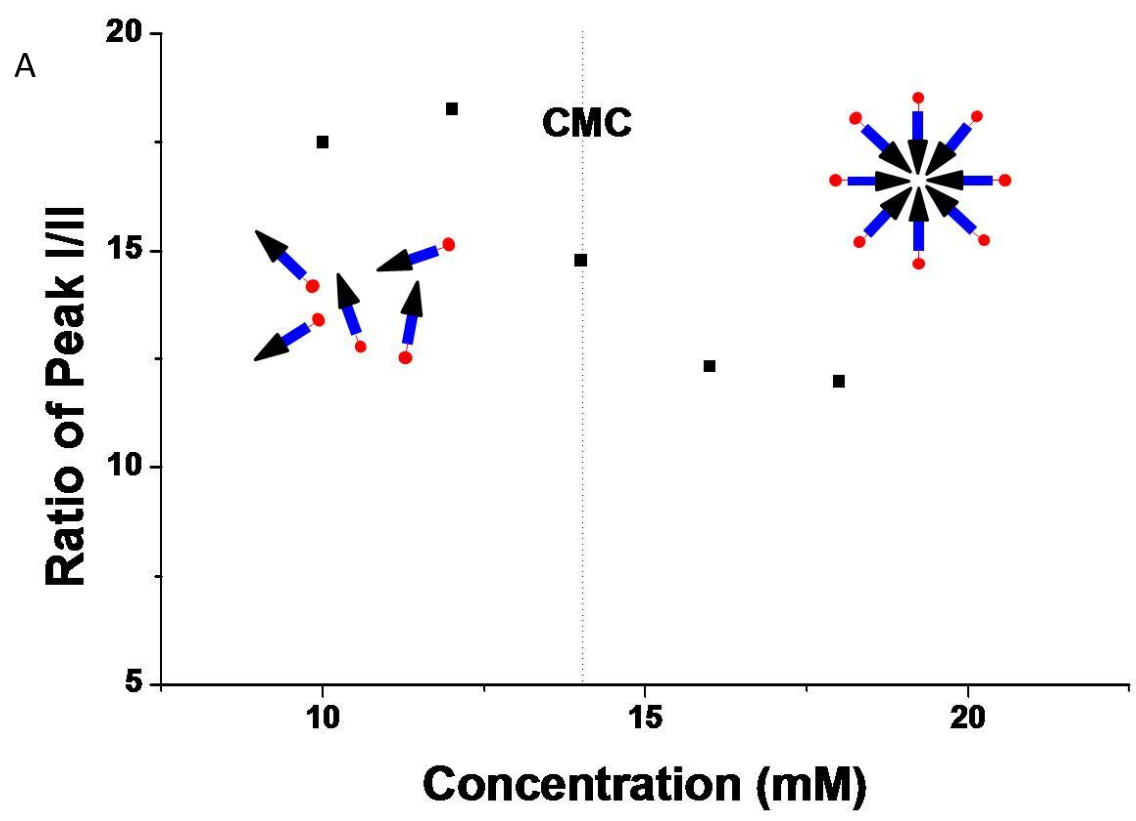

B
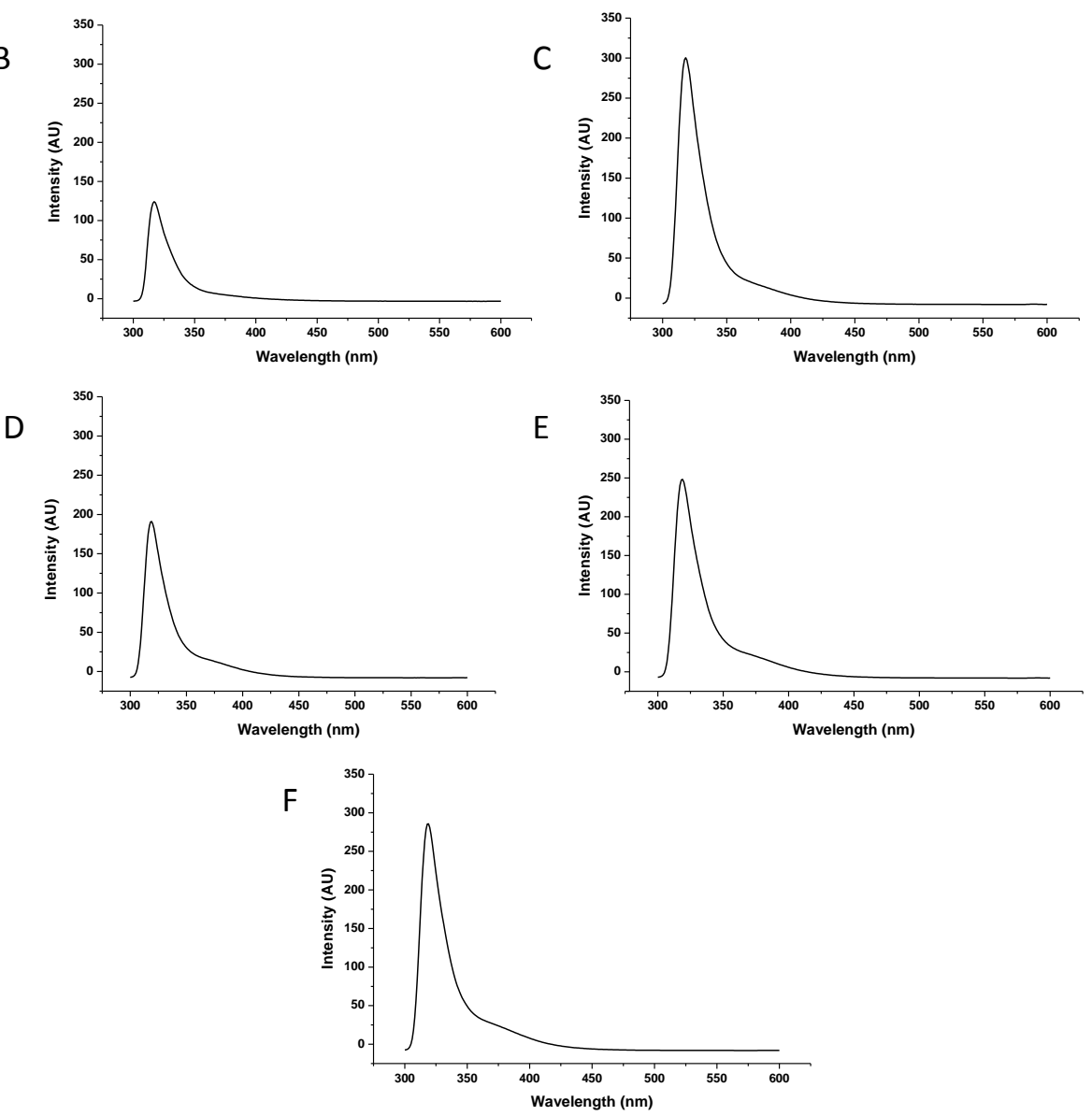

Figure S2. Critical Micelle Concentration (CMC) of Fmoc- $p$ Y with a proposed micelle structure (A). The CMC was determined through the ratio of Peaks I:III ( 320 and $375 \mathrm{~nm}$ respectively) detected through fluorescence spectroscopy after $\lambda_{\mathrm{exc}}$ at $295 \mathrm{~nm}$ for a range of Fmoc- $p$ Y solutions - $10 \mathrm{mM}(\mathrm{B}), 12 \mathrm{mM}(\mathrm{C}), 14 \mathrm{mM}(\mathrm{D}), 16 \mathrm{mM}$ (E) and $18 \mathrm{mM}$ (F). The results suggest a CMC of $14 \mathrm{mM}$. 

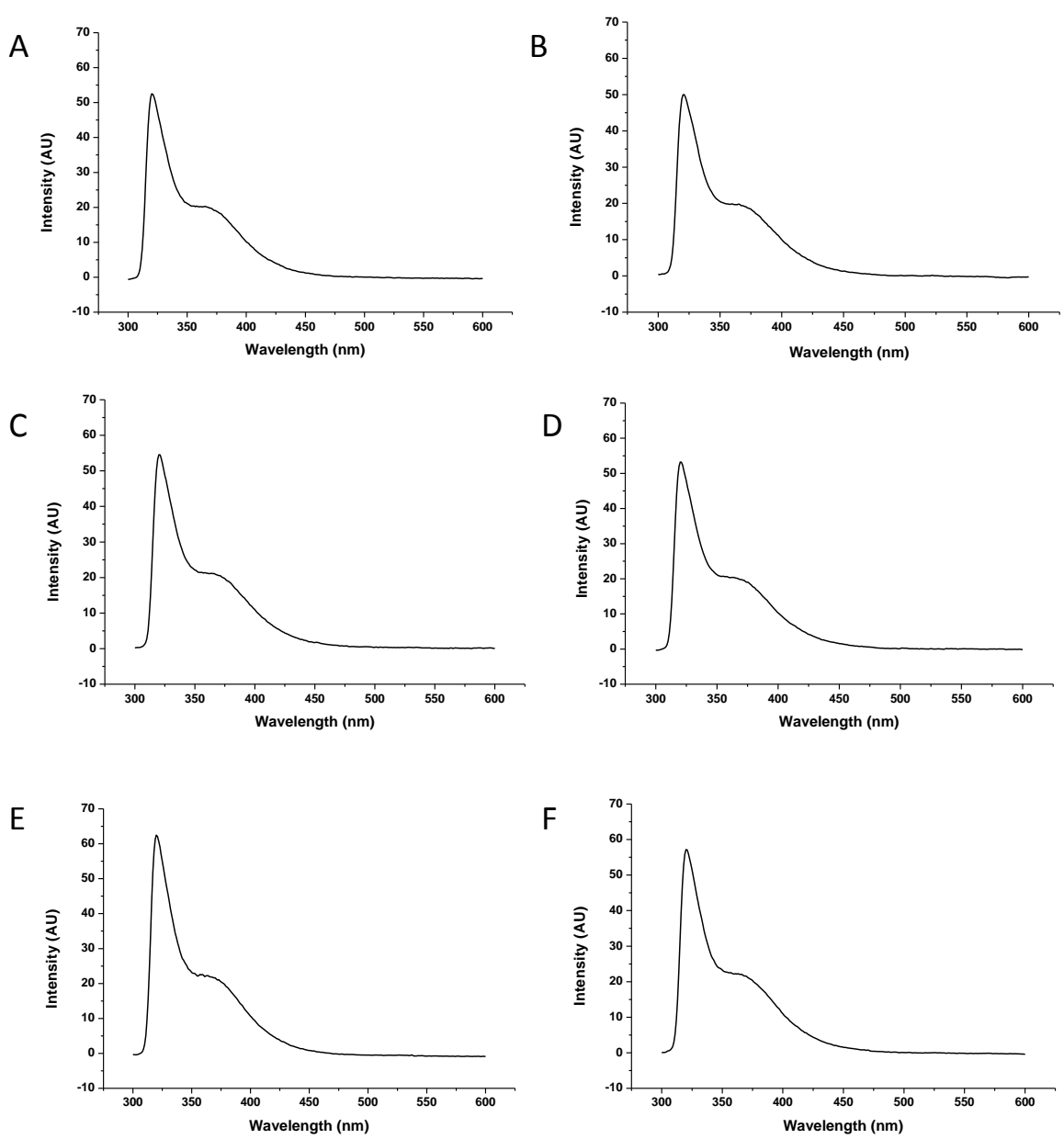

Figure S3. The individual fluorescence spectra of Fmoc- $p \mathrm{Y}(40 \mathrm{mM})$ without AP addition to demonstrate no significant changes were observed in this solution $(\lambda \mathrm{exc}=295 \mathrm{~nm})$. To ensure similarities in concentration an equivalent volume of phosphate buffer was added at $\mathrm{T}=0$ (A) and regular readings were taken after this. The graphs shown here are after $10 \mathrm{mins}(\mathrm{B}), 30 \mathrm{mins}(\mathrm{C}), 1$ hour (D), 2 hours (E) and 4 hours (F). 

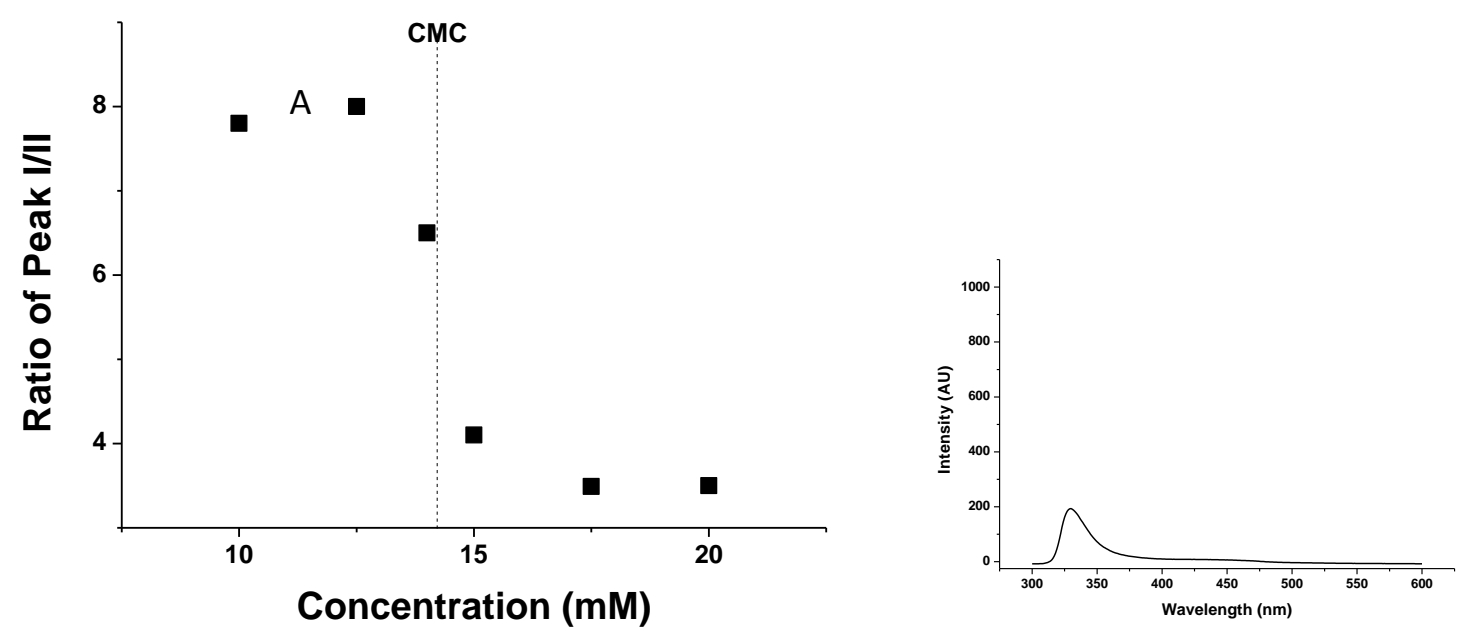

B
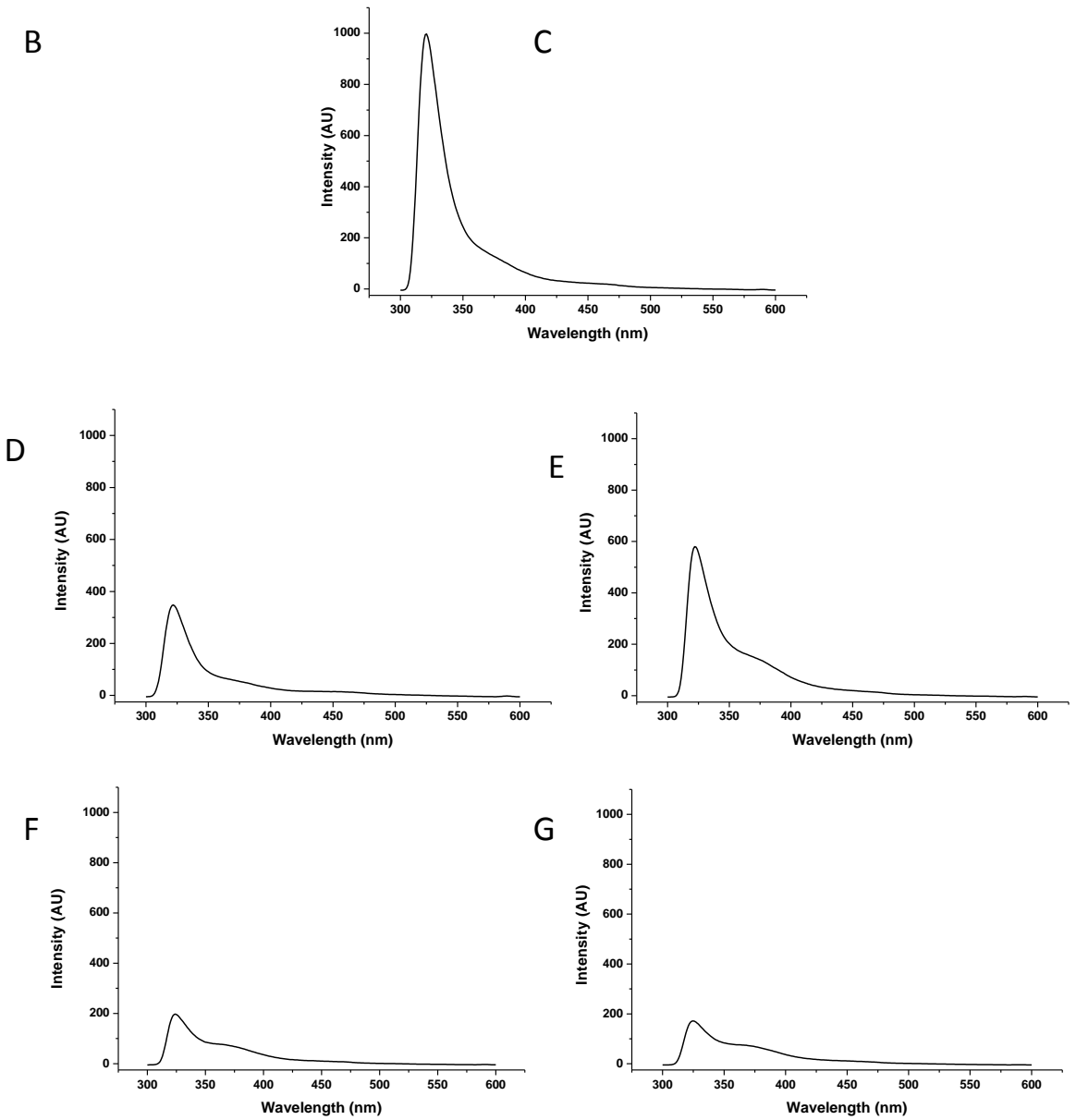

Figure S4. Critical Micelle Concentration (CMC) of Fmoc-Y (A). The CMC was determined through the ratio of Peaks II:III (325 and $375 \mathrm{~nm}$ respectively( detected through fluorescence spectroscopy after $\lambda_{\text {exc }}$ at $295 \mathrm{~nm}$ for a range of Fmoc-Y solutions $10 \mathrm{mM}$ (B), $12.5 \mathrm{mM}(\mathrm{C}), 13.5 \mathrm{mM}(\mathrm{D}), 15 \mathrm{mM}(\mathrm{E}), 17.5 \mathrm{mM}(\mathrm{F})$ and $20 \mathrm{mM}(\mathrm{G})$, suggesting a CMC of $14 \mathrm{mM}$. 
A

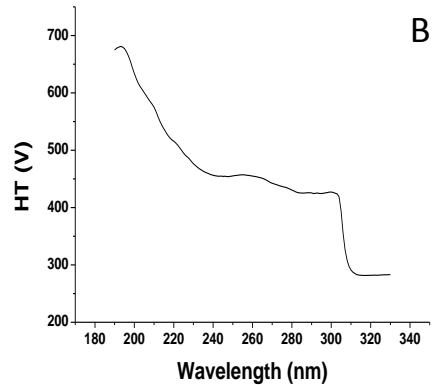

$\mathrm{D}$

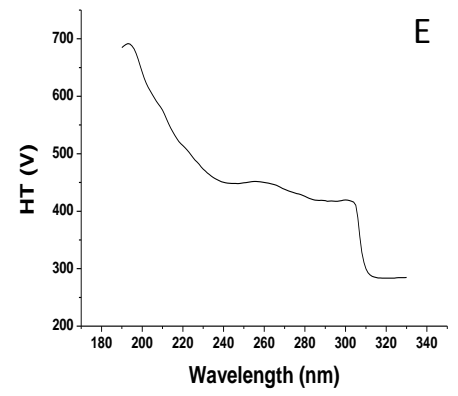

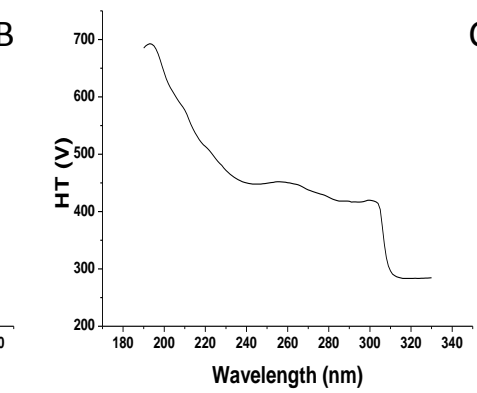
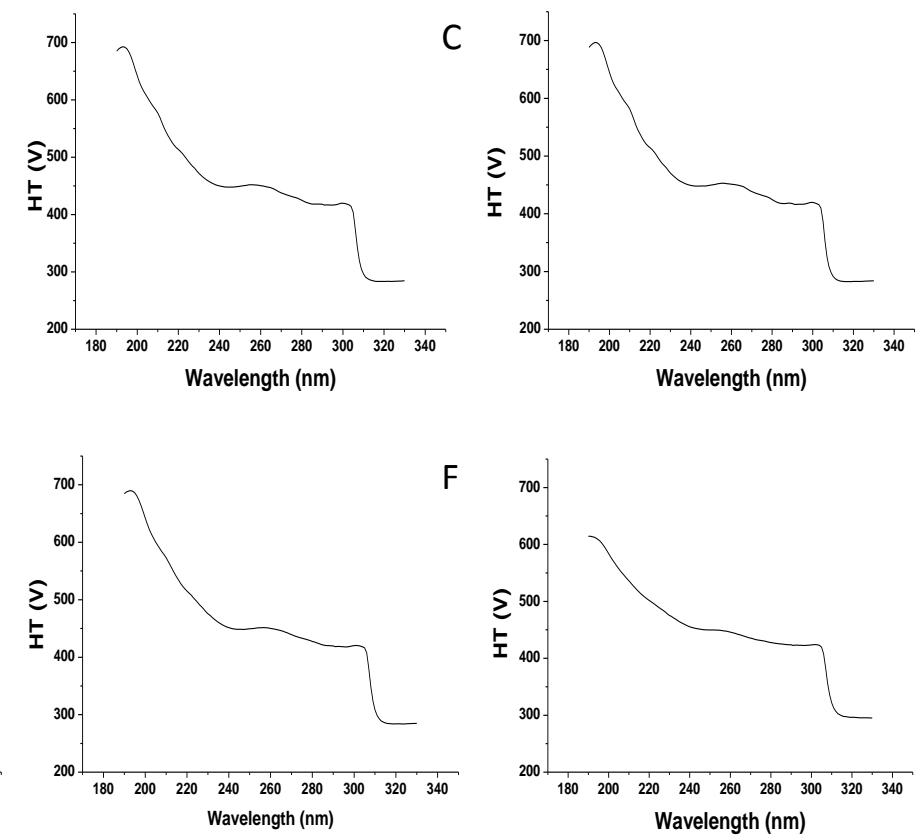

Figure S5. The average photomultiplier tube (PMT) voltage while gathering the CD spectra of the AP triggered (at $3.3 \times 10^{-2}$ mgs protein) hydrogels of Fmoc-Y over time given in Figure 5-6. Time points: A -0 mins, B -10 mins, $\mathrm{C}-30$ mins, D -60 mins, $\mathrm{E}-120$ mins and $\mathrm{F}-240$ mins. When the current voltage exceeds 500 the data obtained at wavelengths less than this are unreliable due to high signal to noise ratio. 


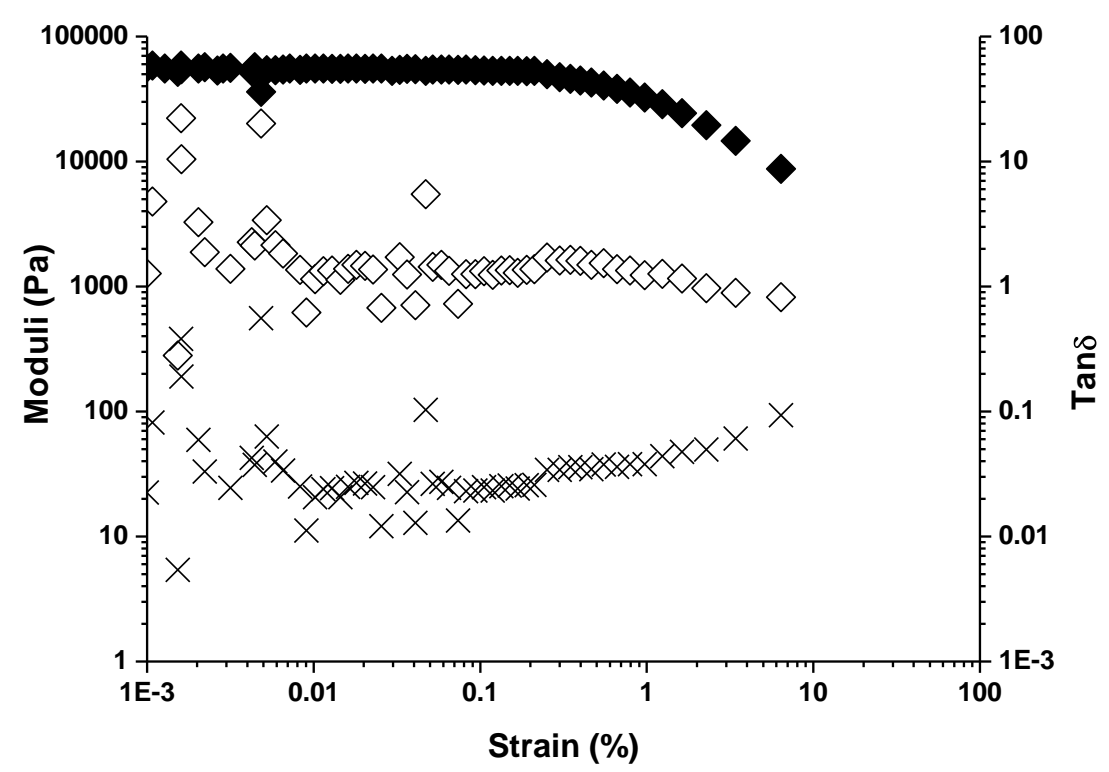

Figure S6. Amplitude sweep completed after the timed oscillatory rheology study to prove that the strain chosen for the timed study $(0.1 \%)$ was within the linear viscoelastic region of the hydrogels formed. Therefore all the changes in the mechanical properties are a result of gelation and fibre formation.

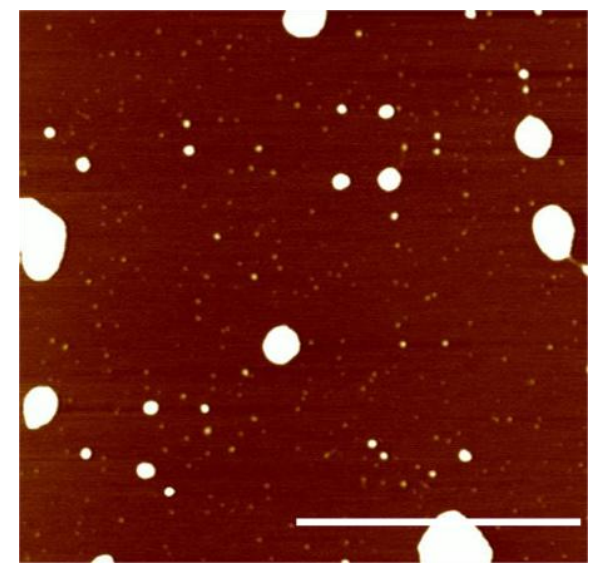

Figure S7. Alkaline phosphatase at $0.11 \mathrm{mgs}$ protein in phosphate buffer $(0.6 \mathrm{M})$ on mica, chosen over glass for its regular topography. The larger aggregates are believed to be salt crystals. The smaller particles are believed to be alkaline phosphatase with an average width of $29 \pm 24 \mathrm{~nm}$ and an average height of $6.0 \pm 5.4 \mathrm{~nm}(\mathrm{n}=30)$. 